\title{
Neural Circuitry Underlying Waking Up to Hypercapnia
}

\section{Satvinder Kaur* and Clifford B. Saper}

Department of Neurology, Program in Neuroscience, Beth Israel Deaconess Medical Center and Harvard Medical School, Boston, MA, United States

Obstructive sleep apnea is a sleep and breathing disorder, in which, patients suffer from cycles of atonia of airway dilator muscles during sleep, resulting in airway collapse, followed by brief arousals that help re-establish the airway patency. These repetitive arousals which can occur hundreds of times during the course of a night are the cause of the sleep-disruption, which in turn causes cognitive impairment as well as cardiovascular and metabolic morbidities. To prevent this potential outcome, it is important to target preventing the arousal from sleep while preserving or augmenting the increase in respiratory drive that reinitiates breathing, but will require understanding of the neural circuits that regulate the cortical and respiratory responses to apnea. The parabrachial nucleus $(\mathrm{PB})$ is located in rostral pons. It receives chemosensory information from medullary nuclei that sense increase in $\mathrm{CO} 2$ (hypercapnia), decrease in $\mathrm{O} 2$ (hypoxia) and mechanosensory inputs from airway negative pressure during apneas. The PB area also exerts powerful control over cortical arousal and respiration, and therefore, is an excellent candidate for mediating the EEG arousal and restoration of the airway during sleep apneas. Using various genetic tools, we dissected the neuronal sub-types responsible for relaying the stimulus for cortical arousal to forebrain arousal circuits. The present review will focus on the circuitries that regulate waking-up from sleep in response to hypercapnia.

Keywords: obstructive sleep apnea, arousal, parabrachial nucleus, calcitonin gene related peptide, hypercapnia

\section{INTRODUCTION}

Obstructive sleep apnea (OSA) is caused by a sleep state-dependent reduction in the pharyngeal dilator muscle activity that leads to the closure of the upper airway in the susceptible individuals. These recurrent episodes of complete or partial obstruction of the upper airway lead to the airway collapse, which causes periodic hypoxia and hypercapnia during sleep, causing brief arousals that restore airway patency (Schulz, 2010; Mannarino et al., 2012; White and Younes, 2012; White, 2017; Darquenne et al., 2018; Pham et al., 2018). These repeated arousals result in sleep disruption, which in turn causes cognitive impairment as well as cardiovascular and metabolic morbidities (Bonnet, 1985; Fletcher, 1996; Bennett et al., 1998; Malhotra and White, 2002; Jun and Polotsky, 2009; Malhotra and Loscalzo, 2009; Drager et al., 2010; Bonsignore et al., 2012). The transient cortical arousals and sleep fragmentation are associated with the autonomic dysregulation, increased oxidative stress and hemodynamic changes during sleep. In patients with OSA, these consequences have been linked to increased daytime sleepiness, cardiovascular and metabolic morbidities. Due to 
this, many OSA patients are also at risk of developing arterial hypertension, coronary heart disease, stroke, type 2diabetes and mortality.

Although OSA can be treated effectively with continuous positive airway pressure, many patients do not tolerate it and compliance is often poor. One alternative therapeutic approach in OSA may involve modifying the arousal threshold that may augment respiratory drive during apnea and recruiting the upper air way muscles to reestablish stable breathing (Horner et al., 1991; Loredo et al., 1999; Horner et al., 2017; Sands et al., 2018; Zinchuk et al., 2018). However, designing drugs that can selectively reduce cortical arousals while maintaining or augmenting the respiratory drive during these respiratory events would require understanding the circuits that mediate cortical EEG and respiratory responses to apnea. This review will focus on recent attempts to identify that circuitry, in particular, using newer methods such as optogenetics and chemogenetics that allow selective, genetically directed targeting of the neuronal nodes that mediate cortical EEG and respiratory responses to apnea.

The brain circuitry that underlies waking up to hypercapnia (increased CO2) that can occur in apnea is not clearly understood. Briefly, three main sensory stimuli that alert the brain during apnea are hypoxia, hypercapnia and negative air pressure in the airways created due to increased respiratory efforts (sensed by mechanoreceptor fibers in vagus) during apneas (White, 2006, 2017). The carotid body primarily senses the hypoxia and to a lesser extent the hypercapnia, and transmits that information to the nucleus of the solitary tract (NTS) via the carotid sinus branch of the glossopharyngeal nerve (Massari et al., 1996; Lindsey et al., 2018). In addition, the chemosensory neurons in the retrotrapezoid nucleus (RTN) directly sense the $\mathrm{CO} 2$, and these project in parallel to the NTS to the ventrolateral medulla (VLM- pattern generator for breathing), and parabrachial nucleus (PB- relay node for visceral sensory information from the brainstem to the forebrain) (Dean et al., 1989; Herbert et al., 1990; Finley and Katz, 1992; Massari et al., 1996; Guyenet et al., 2010a; Bochorishvili et al., 2012; Guyenet and Bayliss, 2015; Lindsey et al., 2018; Figure 1A). The serotonergic raphe system in the brainstem (Richerson et al., 2001; Depuy et al., 2011) and orexin neurons in the lateral hypothalamus (Hunt et al., 2016; Rodrigues et al., 2019), are other CO2 sensing neurons, which also project to the NTS, the VLM, and the PB. In patients with OSA, arousal correlates closely with the airway negative pressure, to a lesser degree to the level of hypercapnia, and least with the level of hypoxia (Gleeson et al., 1990). However, all the three stimuli converge in the same brain locations; therefore studying these areas and their connections is important to understand the brain response to apnea.

\section{PARABRACHIAL NUCLEUS AND CORTICAL AROUSAL}

The $\mathrm{PB}$, a relay node for sensory visceral information, that surrounds the superior cerebellar peduncle, is referred to as the "Pontine taste area" (Saper, 2016) and the same region as early as 1920s was also identified as the "pneumotaxic center" or the "pontine respiratory group" by the workers on respiratory control (Feldman et al., 1976; Dobbins and Feldman, 1994). Recent studies have associated the PB with cortical arousal. In addition to the canonical, cholinergic (Semba and Fibiger, 1992; Steriade et al., 1993; Kleiner and Bringmann, 1996; Datta and Siwek, 1997; Cape and Jones, 2000) and monoaminergic (AstonJones and Bloom, 1981; Berridge and Wifler, 2000) arousal pathways from the upper brainstem, the $\mathrm{PB}$ projects to the thalamus, hypothalamus, and cerebral cortex (Saper and Loewy, 1980; Steriade et al., 1993; Jones, 2005). Surprisingly, cell specific lesions of the cholinergic and monoaminergic neurons, either alone or in combination, in these pontine areas have been found to cause little alteration in wake in both cats and rats (Jones et al., 1973; Holmes and Jones, 1994; Lu et al., 2006; BlancoCenturion et al., 2007; Fuller et al., 2007), whereas large PB lesions cause profound coma (Fuller et al., 2011). Studies from our lab and others have shown that cortical arousal can be induced by activation of PB (Hayashi et al., 2015; Qiu et al., 2016; Kaur et al., 2017) and the deletion of glutamatergic signaling in PB neurons increases sleep and causes EEG slowing (Fuller et al., 2011; Kaur et al., 2013). Therefore, ascending projections of the PB through a ventral forebrain pathway via the hypothalamus and $\mathrm{BF}$ may play a key role in mediating cortical arousal. As the $\mathrm{PB}$ consists of different diverse sub nuclei, each with its distinct input and output targets, and these are often associated with different neuromodulators (Fulwiler and Saper, 1984), it is therefore, necessary to further dissect it using newer genetically specified tools to understand the roles of different cell types in this functionally heterogeneous population.

\section{PARABRACHIAL NUCLEUS AND BREATHING}

$\mathrm{PB}$ receives chemosensory information from RTN and NTS, that sense hypercapnia and hypoxia and also from the upper airway afferents that respond to pulmonary negative pressure associated with apneas (Panneton and Loewy, 1980; Finley and Katz, 1992; Mizusawa et al., 1995; Berquin et al., 2000; Pete et al., 2002; Izumizaki et al., 2004; Rosin et al., 2006; Corcoran et al., 2009; Song and Poon, 2009; Gonzalez et al., 2010; Guyenet et al., 2010b; Topchiy et al., 2010; Bochorishvili et al., 2012; Yokota et al., 2012, 2015; Guyenet and Bayliss, 2015; Roman et al., 2016). As mentioned above, the PB area not only exerts powerful control over cortical arousal (Fuller et al., 2011; Kaur et al., 2013, 2017; Hayashi et al., 2015; Qiu et al., 2016) it also regulates respiration (Miura and Takayama, 1991; Chamberlin and Saper, 1994; Mizusawa et al., 1995; Chamberlin, 2004; Bonis et al., 2010a,b; Diaz-Casares et al., 2012; Damasceno et al., 2014; Kaur et al., 2017; Yang and Feldman, 2018). The ascending projections of the PB mediate cortical arousal (Saper and Loewy, 1980; Saper, 1982; Kaur et al., 2013, 2017; Saper, 2016), while its descending projections to the respiratory areas such as ventral lateral medulla, hypoglossal motor nucleus and phrenic motor nucleus, may regulate respiration (Yokota et al., 2001, 2012, 2015). Thus, the PB is an excellent candidate for a site that 
can augment the airway dilator muscles, particularly following EEG arousals during sleep apneas. However, the precise brain circuitries that can be selectively targeted to prevent cortical arousal but augment respiration and maintain air-way patency during apneas need to be investigated.

\section{MOUSE MODEL OF APNEA}

We designed a mouse model of apnea (Kaur et al., 2013) to simulate breathing during apneas and understand the brain circuitry underlying the repetitive arousals during apnea. Briefly, a mouse is kept in a plethysmograph chamber, and every $300 \mathrm{~s}$, the gas mixture entering the chamber is switched for $30 \mathrm{~s}$ to one that contains either increased CO2 (10\%), reduced O2 (10\%) or both. The gasses mix in the chamber and approach the new steady state after about $10-15 \mathrm{~s}$. At the end of the $30 \mathrm{~s}$ period, the source is switched back to air, and the gas levels return to baseline. We continuously record the EEG and EMG, the plethysmograph (which gives us tidal volume and respiratory rate) and percentage of $\mathrm{CO} 2$ and $\mathrm{O} 2$ in the chamber (Figure 1). In our earlier study, the arousal kinetics to $\mathrm{CO} 2$ (hypercapnia alone) and to the combined hypercapnia and hypoxia were identical (Kaur et al., 2013), therefore we continue to test EEG arousals with hypercapnia in our model (Figures 1B,C), and we will refer here only to the trials with elevated $\mathrm{CO} 2$. We used this paradigm of repetitive hypercapnia as a model of sleep apnea as the duration of the gas disturbance, its frequency, and the length of the arousals, were similar to those seen in a patient with mild sleep apnea. Also hypercapnia is mechanistically more relevant than hypoxia in sleep disordered breathing related neuro-impairment (Wang et al., 2014, 2016), even though the effect of hypoxia only is more extensively studied by most groups.

\section{GENETIC TOOLS AND TECHNOLOGIES FOR CIRCUIT ANALYSIS}

In the past, researchers have used a wide range of electrophysiological and molecular tools, either individually or in combination, to probe and manipulate neural circuits. Although, these had helped us understand some basic pathways,

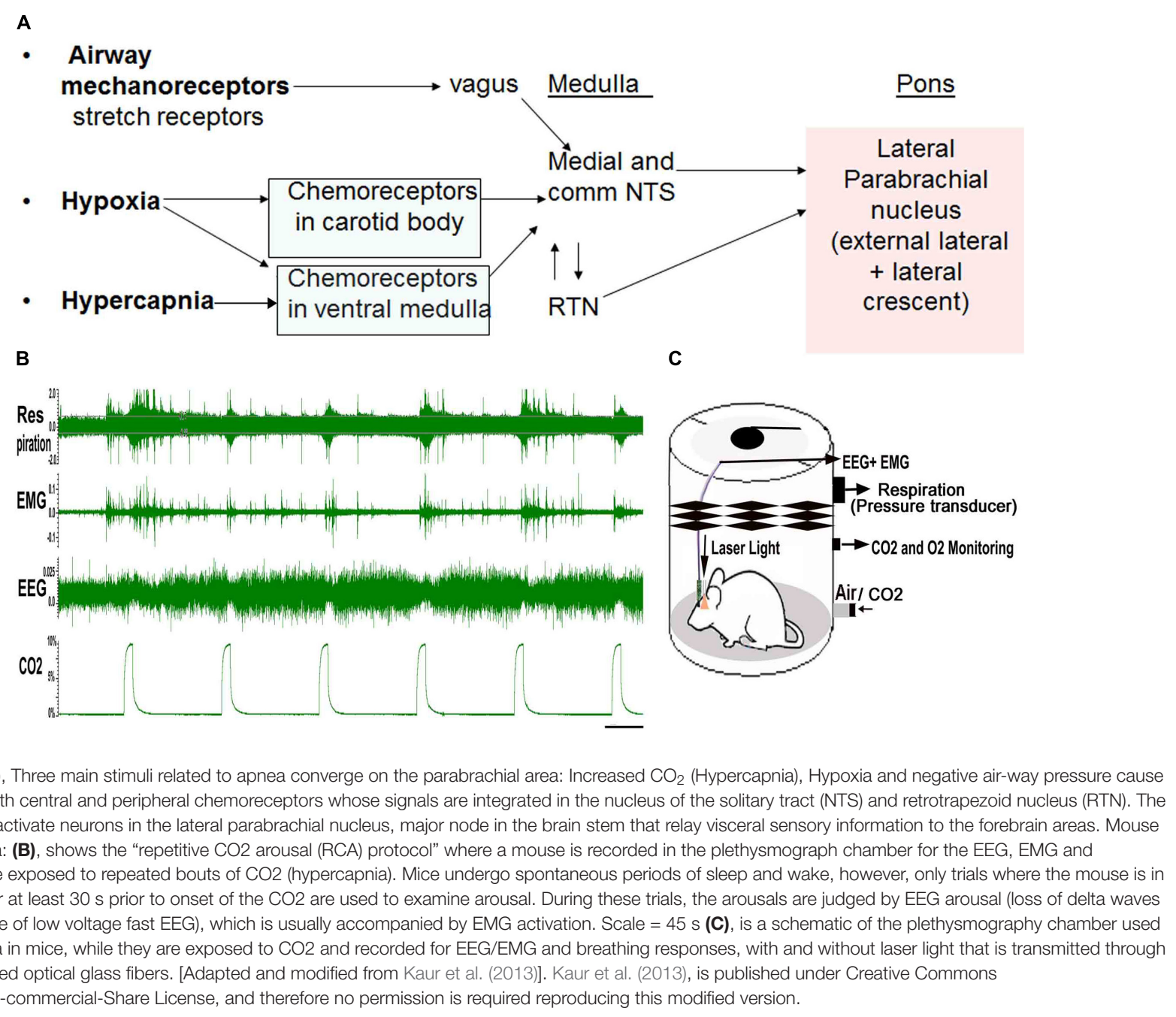


the inherent heterogeneity of brain cells and the lack of target specificity of these earlier tools make the interpretation of such data difficult. For example, pharmacological approaches using receptor agonists and antagonists have been confounded by poor blood-brain permeability when given systemically; low solubility when given directly into the brain; and "off-target" side effects when they engage unintended targets. Other approaches that involve the use of the global gene knockout, sometimes suffer from low temporal and spatial resolution and such approaches can also be confounded by ontogenetic and ectopic expression of the gene of interest. Similarly, both acute and chronic lesions produce collateral damage to adjacent brain structures making it difficult to interpret the effects which could be secondary to the lesion itself. Now, the emergence of newer conditional genomic models and viral-vectors approaches allow us to precisely target a selective cell population in the brain area of interest, and this is helping to link specific group of neurons and neural pathways to specific behaviors (Carter et al., 2010, 2013b; Carr and Zachariou, 2014; Fuller et al., 2015; Han et al., 2015; Campos et al., 2016, 2018; Qiu et al., 2016; Whissell et al., 2016; Saper and Fuller, 2017; Wu et al., 2018). The introduction of the Cre transgenes through gene delivery methods using the Cre/ lox system provides better temporal and spatial control over Cre-mediated excision of a selective gene sequence encoding the protein of interest (Kaur et al., 2013; Abbott et al., 2014; Todd et al., 2018), in a selective brain area (Figure 2C).

In recent years, the use of chemo- and opto-genetic tools had equipped us with an unparalleled ability to probe the neural circuitry that underlies behavioral state. The genetically engineered receptors are successfully used as tools for targeting chemo- and opto-genetics to selective cell types. Because they are activated either by injectable synthetic ligands that specifically bind to these receptors on the targeted cells and excite or inhibit them (chemogenetics) or through the delivery of specific wavelengths of laser-light via an implanted optical fiber (optogenetics), investigators retain temporal control over particular subsets of neurons (Fuller et al., 2015; Park and Carmel, 2016; Vlasov et al., 2018). In addition, because the opto- or chemogenetic tool is expressed in a conditional manner, it is only expressed by cells of a specific genotype, thus giving the investigator both neuroanatomical and neurochemical control over the response. Because the receptor transcript is packaged within a Flip-Excision-Switch (FLEX) cassette, the functional receptor can be expressed only in the presence of cre-recombinase (Schnutgen et al., 2003; Fuller et al., 2015; Plummer et al., 2017). The use of the Cre-driver mouse lines,
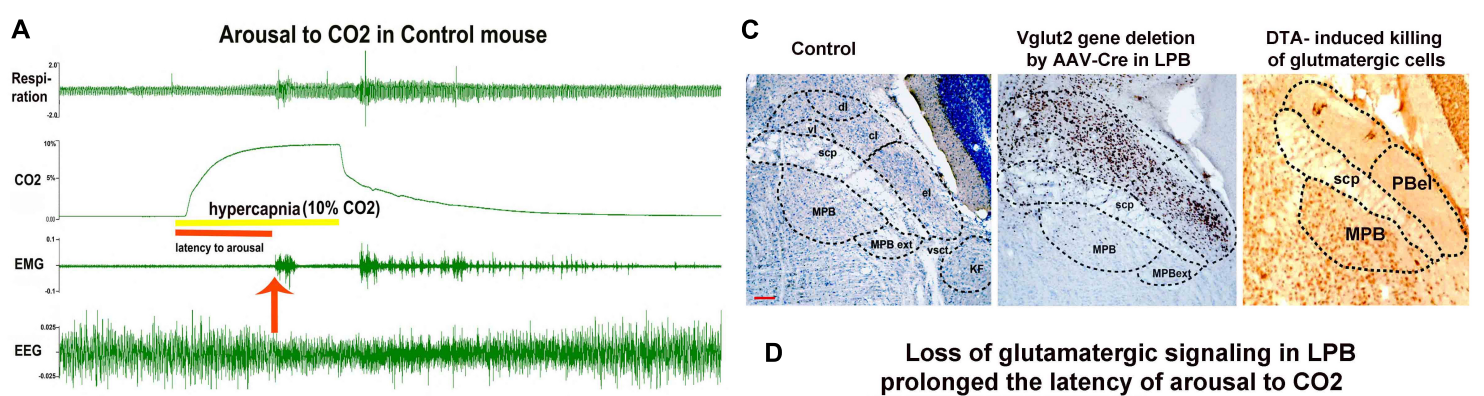

D Loss of glutamatergic signaling in LPB
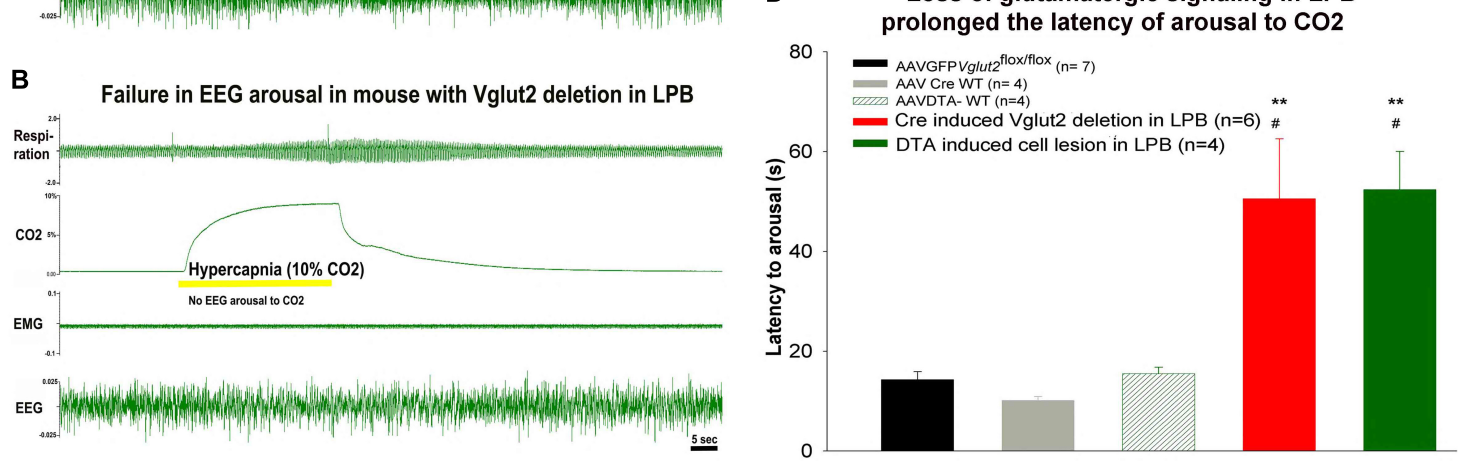

FIGURE 2 | Testing the role of glutamatergic signaling in hypercapnia induced arousal: (A,B), are the two representative trials from a control mouse (A), where cortcial EEG arousal in response to hypercapnia occurs in $15 \mathrm{~s}$ after onset of CO2, while the mouse with deletion of Vglut2 gene in the LPB (B), fails to wake wake up to hypercapnia. (C), Photomicrograph of the Nissl-stained coronal section of the mouse brain, showing different sub divisions of the parabrachial (PB) nucleus, Cre-immunoreactivity (brown) against a Nissl-stained background (blue) in the neurons in the lateral parabrachial (LPB) region after injection of AAV-Cre in Vglut2 flox/flox mice and last panel shows the shows a photomicrograph of a brain section immunostained for Neu-N, a neuronal marker after bilateral injection of AAV-DTA killed Vglut2+ neurons into the LPB. (D), Show graphs of the latency of arousal during and after a hypercapnic stimulus of $30 \mathrm{~s}$ in mice injected bilaterally with AAV-DTA (green) compared to the control (black, gray, and striped green) and LPB group from which Vglut2 was deleted in the LPB including the PBel (red). scp superior cerebellar peduncle; dl - dorso-lateral; cl - centro-lateral; el - external lateral; vl - ventrolateral PB subnucleus; MPB - medial and MPB-ext - medial external-lateral parabrachial nucleus; KF - Kolliker Fuse; vsct - ventral cerebro-spinal tract; Scale $=100 \mu \mathrm{m}$. **represents $p<0.01$ compared to the control group (AAV-GFP) and ${ }^{\#} p<0.05$, compared to the AAVCreWT group. [Adapted and modified from Kaur et al. (2013)]. Kaur et al. (2013), is published under Creative Commons Attribution-Non-commercial-Share License, and therefore no permission is required reproducing this modified version. 


\section{A Using Chemogenetics}

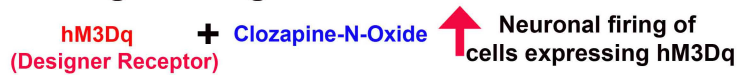

A1

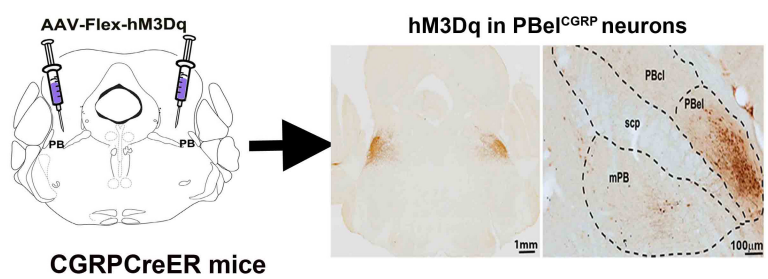

\section{B Using Optogenetics}

B1

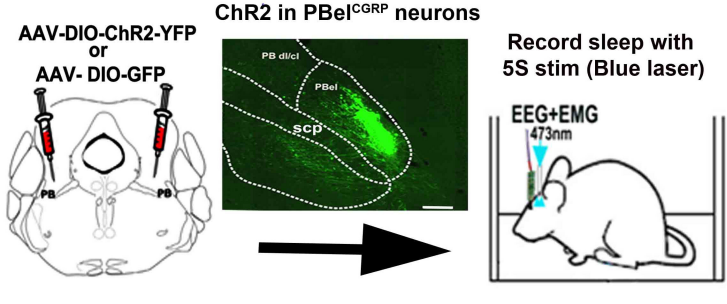

CGRPCreER mice
A2 Increased wakefulness for $\mathbf{2 h}$

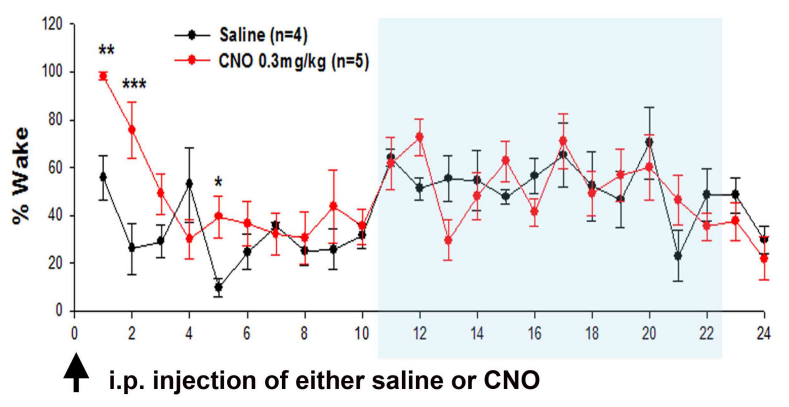

B2 Produce short latency cortical arousals

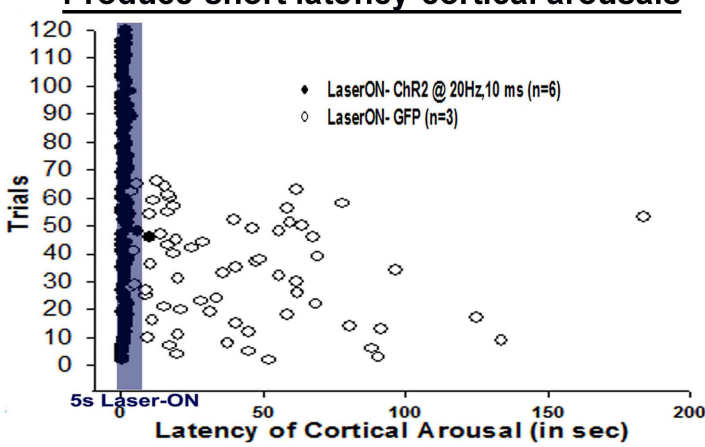

FIGURE 3 | Selective activation of the PBelCGRP neurons, using chemogenetics (A) and optogenetics (B): The (A1,B1) represent the strategy used to first express

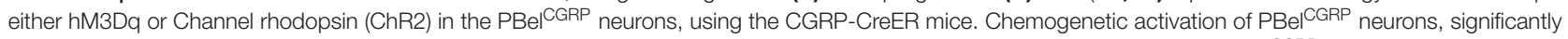
increased wakefulness for $2 \mathrm{~h}$ post injection of the designer ligand (CNO) that binds hM3Dq (A2). Optogenetically driving the PBel ${ }^{\text {CGRP }}$ neurons also produced very short latency arousals both at 10 and $20 \mathrm{~Hz}$, trials shown in the figure are from stimulation at $20 \mathrm{~Hz}$ (B2). $\left({ }^{* * *} p<0.0001 ;{ }^{* *} p<0.001 ; 1\right.$-way or repeated measures ANOVA followed by Holm-Sidak for multiple comparison). [Adapted and modified from Kaur et al. (2017)]. Kaur et al. (2017) is published in a Cell Press journal "Neuron," and no permissions needed to reproduce the modified versions of the published figure.

where cre is expressed downstream of a selected promoter, ensures that the designer receptors when injected in these mice are expressed in a Cre-dependent manner, specifically in neurons that express a select protein. Finally, because the viral vectors for the opto- and chemogenetic tools can be injected locally in the brain, the investigator also has spatial control over the part(s) of the brain involved in the experiment. These modified receptors can act as effective tools that allow us to manipulate a selective neural circuit and we can then evaluate the effect upon the behavior in direct relation to either the excitation or inhibition of a specific neuronal node.

\section{GLUTAMATERGIC SIGNALING IN THE PB AND WAKING UP TO CO2}

To examine the role of glutamatergic signaling in the $\mathrm{PB}$, in one set of animals we deleted the vesicular glutamate transporter-2 (Vglut2) gene in various PB sub-nuclei (by injecting an AAVCre into the $\mathrm{PB}$ of Vglut $2^{\text {flox/flox }}$ mice). In another set of mice, we killed the cells in the lateral $\mathrm{PB}$ using injections of AAV that had Cre-dependent expression of diphtheria toxin subunit A (DTA) in Vglut2-Cre mice (Figure 2C). We tested these mice for arousal to hypercapnia using the mouse model of apnea (Figure 1). Our results indicated that deletion of glutamatergic signaling from neurons in the external lateral PB (PBel), or killing the Vglut2 neurons in the PBel produced the same prolongation of the latency of waking up to $\mathrm{CO} 2$ (Figures 2A-D), suggesting that glutamate alone in PBel neurons is the operative neurotransmitter for relaying the signal for waking up from sleep in response to hypercapnia (Kaur et al., 2013). Many neurons in the PBel express calcitonin gene related peptide [CGRP, (Yasui et al., 1991); $\mathrm{PBel}^{\mathrm{CGRP}}$ ], and we tested whether these are activated (cFos expression) in response to the hypercapnia (Yokota et al., 2015). Most of the cFos positive neurons in the PBel contained CGRP, while many along the lateral edge of the nucleus did not. Because most PBel ${ }^{\text {CGRP }}$ neurons project to the forebrain, whereas most neurons lateral to them project to the brainstem, we hypothesized that the PBel ${ }^{\text {CGRP }}$ neurons might be selectively responsible for forebrain arousal during hypercapnia.

\section{ROLE OF THE PBEL CGRP NEURONS IN CORTICAL AROUSAL}

Using optogenetic and chemogenetic tools in CGRP-CreER mice (Kaur et al., 2017), we could selectively activate and inhibit the 


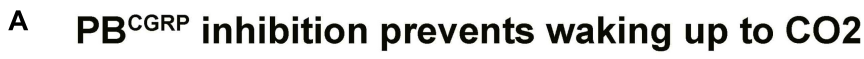
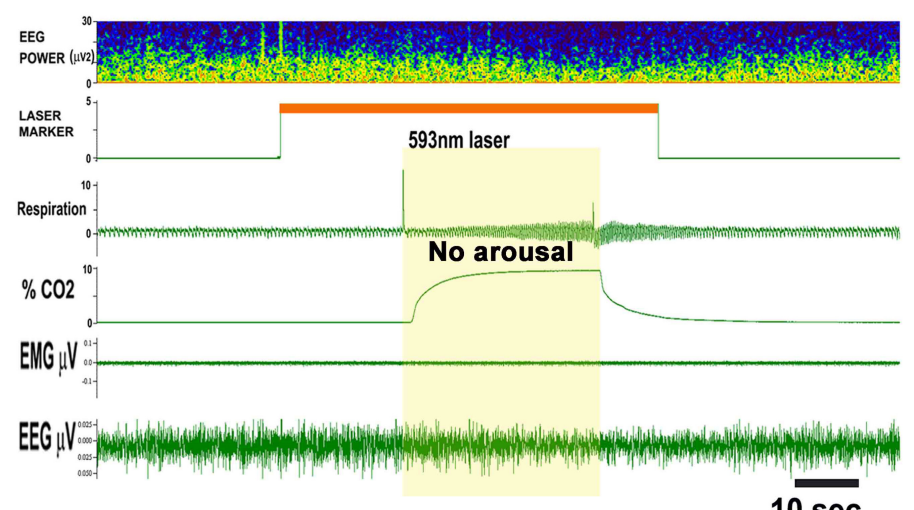

B No change in ventilatory effort to $\mathrm{CO} 2$
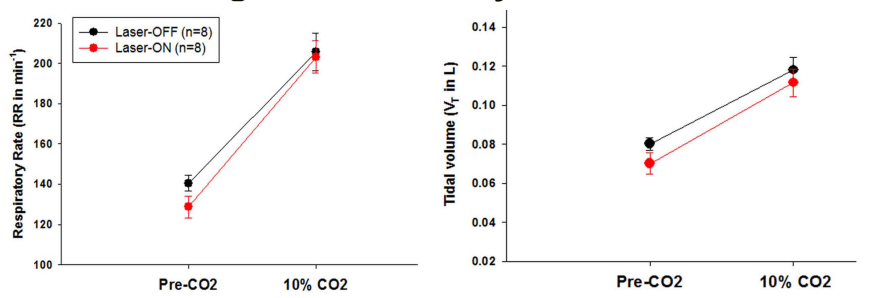

c Comparison soma inhibition vs. the terminal fields
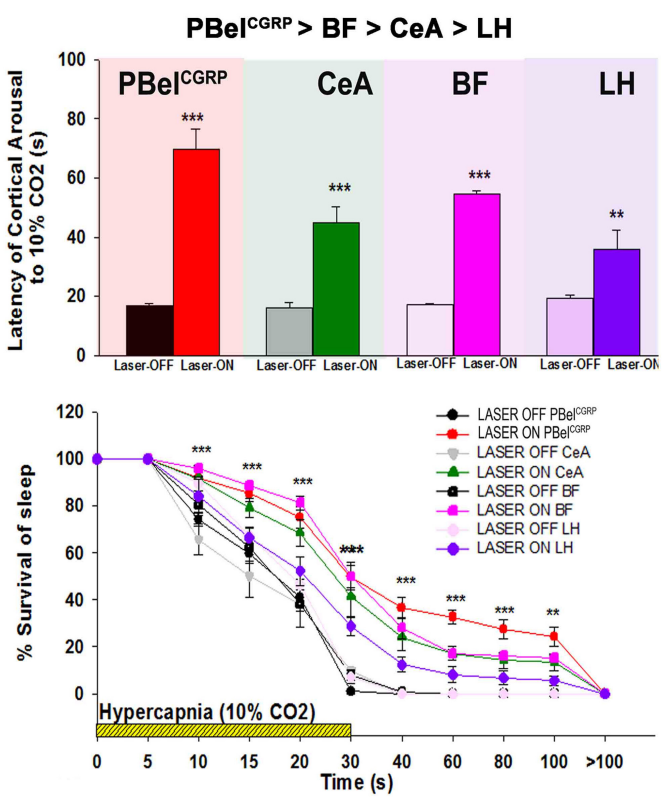

FIGURE 4 | Selective silencing of the PBel ${ }^{\text {CGRP }}$ neurons and the terminal fields using Optogenetics: (A), is the representative recording of EEG, EMG and respiration during the 10\% CO2 stimulus in a CGRP-CreER mouse with laser photo-inhibition of PBel ${ }^{\text {CGRP }}$ neurons, the mouse in this representative trial did not wake up, and had similar increase in the ventilatory-drive in response to $\mathrm{CO} 2$ as the control with Laser-OFF. (B), Left panel, are the graphs comparing the respiratory rate (RR) and the tidal volume $\left(\mathrm{V}_{T}\right)$ (right panel) for 3 breaths before CO2 (Pre CO2) and for 3 breaths during CO2 just prior to waking-up in Laser-OFF and then at the same time point in trials in the same animal with Laser-ON (in which the animals did not awaken). (C), Compares the effects of PBel ${ }^{\text {CGRP }}$ soma inhibition to that of PBel ${ }^{\text {CGRP }}$ terminals field inhibition (A), latency of arousal mean (SEM) during laser (593 nm) induced inhibition of the PBelCGRP neurons is compared with inhibition of the terminal fields in the BF, CeA, and LH. (B) Survival of sleep curves during and after a hypercapnic stimulus shown with and without laser. (*** $p<0.0001$;

${ }^{* *} p<0.001$; 1-way or repeated measures ANOVA followed by Holm-Sidak for multiple comparison). [Adapted and modified from Kaur et al. (2017)]. Kaur et al. (2017) is published in a Cell Press journal "Neuron," and no permissions needed to reproduce the modified versions of the published figure.

PBel ${ }^{\mathrm{CGRP}}$ neurons. Optogenetic activation of $\mathrm{PBel}^{\mathrm{CGRP}}$ neurons at 10 and $20 \mathrm{~Hz}$ by $10 \mathrm{~ms}$ blue laser light pulses (Figure 3B) caused short latency arousals and their chemogenetic activation significantly increased wakefulness (Figure 3A; Kaur et al., 2017). Targeting yellow $(593 \mathrm{~nm})$ laser light to the archaerhodposin TP009 (ArchT) expressing PBel ${ }^{\text {CGRP }}$ neurons during the CO2 trials, silences them. Mice with inhibition of $\mathrm{PBel}^{\mathrm{CGRP}}$ neurons (Laser-ON) failed to wake up to $\mathrm{CO} 2$ in $50 \%$ of the trials and increased the latency to arousal by four fold in response to the $\mathrm{CO} 2$ (Figre 4A,C). These results were similar to those we obtained with killing most of the lateral PB neurons, or deleting their Vglut2 gene. In other words, the PBel ${ }^{\text {CGRP }}$ neurons appear to provide most if not all of the arousal response to $\mathrm{CO} 2$, by using glutamate as their neurotransmitter.

Interestingly, the silencing of the $\mathrm{PBel}^{\mathrm{CGRP}}$ neurons preserved the respiratory drive (Figure 4B) during the hypercapnia, with no differences in the tidal volume and respiratory rate (Kaur et al., 2017). Also these laser-induced inhibitions did not affect the arousal thresholds to acoustic stimuli or somatosensory and vestibular stimulation (Kaur et al., 2017). Recent work from Palmiter and colleagues suggests that the CGRP neurons may respond to pain and to other visceral stimuli (e.g., gastrointestinal upset or conditioned taste aversion) (Carter et al., 2015; Han et al., 2015; Campos et al., 2018) which has led to the suggestion that they may serve a more generalized central alarm function, waking up the brain when aversive visceral or noxious stimuli arise (Saper, 2016; Palmiter, 2018).

To further investigate the arousal regulating circuitry targeted by $\mathrm{PBel}^{\mathrm{CGRP}}$ neurons for causing arousals during apnea, we inhibited terminal fields at three major forebrain arousal nodes: the substantia innominata in the basal forebrain (BF); the central nucleus of the amygdala (CeA); and the lateral hypothalamus $(\mathrm{LH})$. Optogenetic silencing of these terminals fields also increased the latency for arousal, with differential responses at multiple target sites. Our data suggested that PBel $^{\text {CGRP }}$ neurons act most potently through their direct projections to the $\mathrm{BF}$, whose neurons have direct projections to the cerebral cortex. The CeA also participates in the arousal, but has no ascending projections to the cortex or thalamus. Because it projects intensely to the $\mathrm{BF}$, this is likely to be its mechanism of function. Lastly inhibition of the $\mathrm{PBel}{ }^{\mathrm{CGRP}}$ terminals in the $\mathrm{LH}$ field had the least effect on the arousal in response to $\mathrm{CO} 2$. Although some $\mathrm{LH}$ 


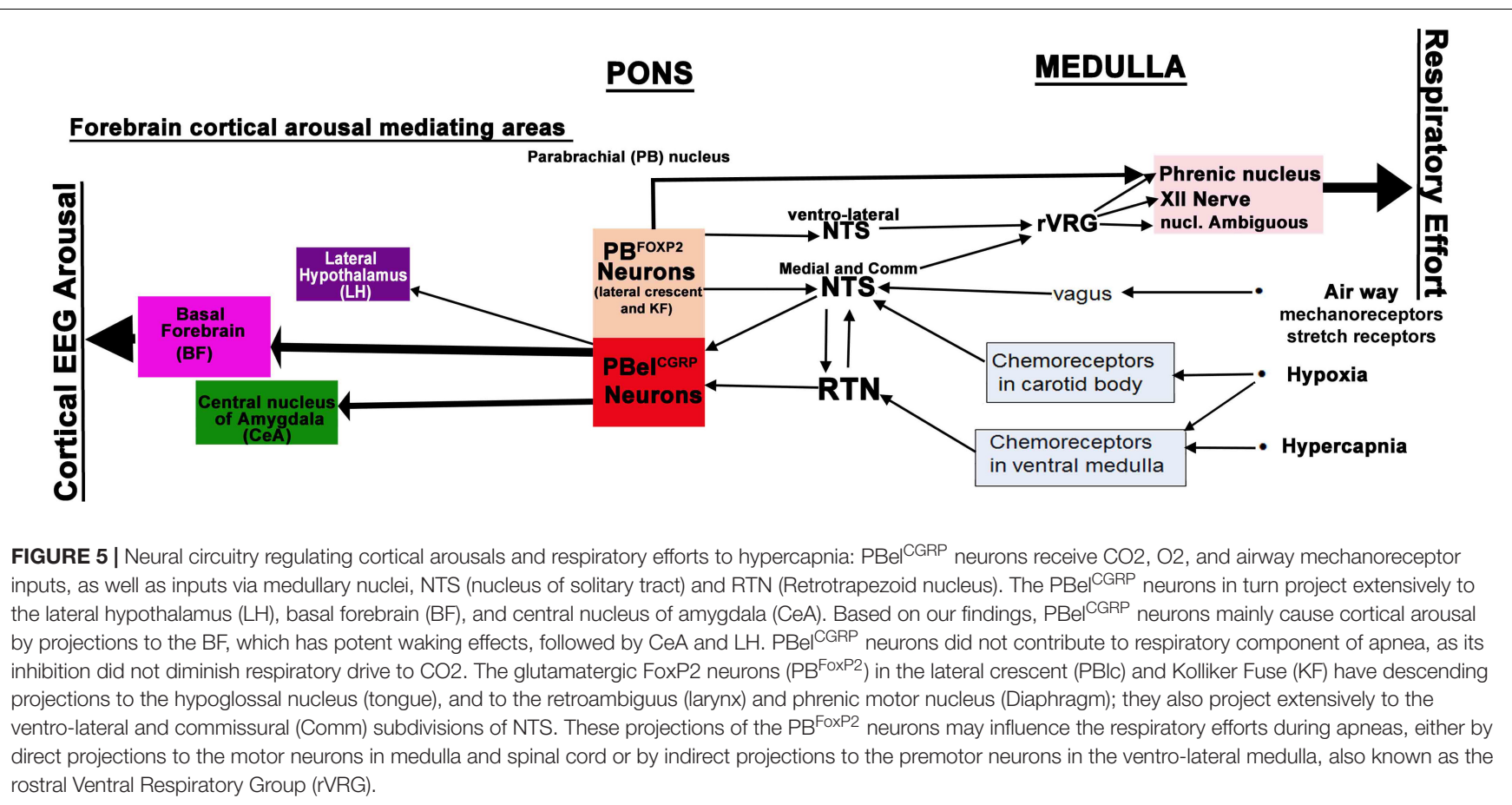

neurons directly project to cerebral cortex and others send axons to the $\mathrm{BF}$, this region appears to play at most a minor role in arousal to $\mathrm{CO} 2$ (Figure $4 \mathrm{C}$ ). Thus, the PBel ${ }^{\mathrm{CGRP}}$ neurons are a critical node in the network that receives input from neural pathways activated in apneas in response to hypercapnia, hypoxia and airway stretching, and in relaying that influence to the forebrain sites to cause awakening during apneas (Figure 5).

$\mathrm{PBel}^{\mathrm{CGRP}}$ neurons did not contribute to the respiratory component of apnea, as their inhibition did not diminish respiratory drive to $\mathrm{CO} 2$. Also, these neurons did not show any descending outputs to the respiratory areas, but adjacent neurons that showed a cFos response to $\mathrm{CO} 2$ in the lateral crescent (PBlc) and Kolliker Fuse (KF), do project to respiratory areas (Yokota et al., 2015). Of note, many of the neurons in this area express the transcription factor Forkhead-homeobox protein2 (FoxP2), which is distributed throughout the respiratory column in both rats and mice (Geerling et al., 2017; Stanic et al., 2018; Figure 5). The glutamatergic FoxP2 neurons in the PBlc and KF have descending projections to respiratory areas such as the ventrolateral medulla including the preBötzinger complex and retroambiguus area, the hypoglossal nucleus, the ventrolateral and commissural subdivisions of NTS, and the intermedio-lateral cell column (IML) and phrenic motor nucleus in the spinal cord (Geerling et al., 2017). These projections, much of which are likely to come from the $\mathrm{PB}^{\mathrm{FoxP} 2}$ neurons, may influence the respiratory efforts during apneas (Figure 5). However, it remains to be seen if selectively manipulating the $\mathrm{PB}^{\mathrm{FoxP} 2}$ neurons in the PBlc and KF can augment ventilatory efforts during hypercapnia. We are now investigating such a role of this population of $\mathrm{PB}^{\mathrm{FoxP} 2}$ neurons in augmenting respiration in response to hypercapnia and their possible interactions with $\mathrm{PB}^{\mathrm{CGRP}}$ neurons.

Other brainstem cell groups, such as the serotonergic dorsal raphe (Richerson et al., 2005; Buchanan and Richerson, 2010; Ray et al., 2011, 2013; Smith et al., 2012) have also been shown to regulate hypercapnia induced arousals. A recent study showed that serotonergic dorsal raphe regulates waking up to $\mathrm{CO} 2$, and this is mediated through $5 \mathrm{HT}_{2 \mathrm{~A}}$ receptors (Smith et al., 2018). However, mice deficient in $5 \mathrm{HT}$ neurons are responsive to the $\mathrm{CO} 2$ when injected with a $5 \mathrm{HT}_{2 A}$ agonist (Buchanan et al., 2015), suggesting that DR serotonergic neurons are modulatory and maybe acting through a non-serotonergic area, e.g., PBel ${ }^{\text {CGRP }}$ neurons (Kaur et al., 2018). This possibility is also the subject of our current investigations.

\section{CONCLUSION}

Effective pharmacotherapy for OSA will depend on identifying the sites that can selectively regulate the brain response to hypercapnia (Horner et al., 2017) and therefore be used as druggable targets. Another line of investigation, with the goal of providing more personalized therapeutic interventions for patients with a low arousal threshold (Sands et al., 2018), seeks to quantify and manipulate the "arousal threshold" in patients with OSA. The knowledge of selective neuro-circuitries that comprise functionally connected specific neurons, such as PBel CGRP and $\mathrm{PB}^{\mathrm{FoxP} 2}$ neurons for regulation of cortical arousal and respiratory efforts during apnea can help with such interventions. Importantly, $\mathrm{PBel}^{\mathrm{CGRP}}$ neurons are not only activated by hypercapnia, but are also responsive to various potentially 
dangerous or aversive stimuli (Carter et al., 2013b,a, 2015; Han et al., 2015; Campos et al., 2016, 2018; Saper, 2016; Palmiter, 2018). As such, it is plausible that different subpopulations of $\mathrm{PBel}^{\mathrm{CGRP}}$ neurons encode and process different classes of aversive stimuli (Bernard et al., 1994; Campos et al., 2018) resulting in amplification of the hypercapnia-arousal response. Therefore, to treat a low arousal threshold in sleep apnea, there is a need for more precise understanding about the afferents that selectively modulate the $\mathrm{PBel}^{\mathrm{CGRP}}$ neurons and therefore likely help tune the hypercapnia-arousal response. Thus, a deeper understanding of the PBel ${ }^{\text {CGRP }}$ neurocircuitry and it's connections to other neuronal subpopulations in the $\mathrm{PB}$ (for e.g., $\mathrm{PB}^{\mathrm{FoxP} 2}$ neurons) and each of their distinct projection targets, will help yield valuable therapeutic targets, that can help prevent cortical arousal during apneas while preserving the respiratory drive important for restoring the airway patency. This will eventually help in preventing OSA and its negative secondary health consequences.

\section{ETHICS STATEMENT}

All animal procedures met National Institutes of Health standards, as described in the Guide for the Care and Use of

\section{REFERENCES}

Abbott, S. B., Holloway, B. B., Viar, K. E., and Guyenet, P. G. (2014). Vesicular glutamate transporter 2 is required for the respiratory and parasympathetic activation produced by optogenetic stimulation of catecholaminergic neurons in the rostral ventrolateral medulla of mice in vivo. Eur. J. Neurosci. 39, 98-106. doi: $10.1111 /$ ejn. 12421

Aston-Jones, G., and Bloom, F. E. (1981). Activity of norepinephrine-containing locus coeruleus neurons in behaving rats anticipates fluctuations in the sleepwaking cycle. J. Neurosci. 1, 876-886. doi: 10.1523/jneurosci.01-08-00876. 1981

Bennett, L. S., Langford, B. A., Stradling, J. R., and Davies, R. J. (1998). Sleep fragmentation indices as predictors of daytime sleepiness and $\mathrm{nCPAP}$ response in obstructive sleep apnea. Am. J. Respir. Crit. Care Med. 158, 778-786. doi: 10.1164/ajrccm.158.3.9711033

Bernard, J. F., Huang, G. F., and Besson, J. M. (1994). The parabrachial area: electrophysiological evidence for an involvement in visceral nociceptive processes. J. Neurophysiol. 71, 1646-1660. doi: 10.1152/jn.1994.71.5.1646

Berquin, P., Bodineau, L., Gros, F., and Larnicol, N. (2000). Brainstem and hypothalamic areas involved in respiratory chemoreflexes: a Fos study in adult rats. Brain Res. 857, 30-40. doi: 10.1016/s0006-8993(99) 02304-5

Berridge, C. W., and Wifler, K. (2000). Contrasting effects of noradrenergic beta-receptor blockade within the medial septal area on forebrain electroencephalographic and behavioral activity state in anesthetized and unanesthetized rat. Neuroscience 97, 543-552. doi: 10.1016/s0306-4522(00) 00047-6

Blanco-Centurion, C., Gerashchenko, D., and Shiromani, P. J. (2007). Effects of saporin-induced lesions of three arousal populations on daily levels of sleep and wake. J. Neurosci. 27, 14041-14048. doi: 10.1523/jneurosci.321707.2007

Bochorishvili, G., Stornetta, R. L., Coates, M. B., and Guyenet, P. G. (2012). PreBotzinger complex receives glutamatergic innervation from galaninergic and other retrotrapezoid nucleus neurons. J. Comp. Neurol. 520, 1047-1061. doi: $10.1002 / \mathrm{cne} .22769$

Bonis, J. M., Neumueller, S. E., Krause, K. L., Kiner, T., Smith, A., Marshall, B. D., et al. (2010a). A role for the Kolliker-Fuse nucleus in cholinergic modulation of breathing at night during wakefulness and NREM sleep. J. Appl. Physiol. 109, 159-170. doi: 10.1152/japplphysiol.00933.2009
Laboratory Animals, and all protocols were approved by the Beth Israel Deaconess Medical Center Institutional Animal Care and Use Committee.

\section{AUTHOR CONTRIBUTIONS}

SK conceptualized, designed the experiments, collected and analyzed the data, and wrote the manuscript. CS contributed to the experimental concept and design, and wrote the manuscript.

\section{FUNDING}

This research work was supported by funding from USPHS grants 2P01 HL095491 and NS085477.

\section{ACKNOWLEDGMENTS}

We thank Quan Ha and Minh Ha for their excellent technical support, and Sathyajit Bandaru for maintaining the mouse breeding program.

Bonis, J. M., Neumueller, S. E., Krause, K. L., Kiner, T., Smith, A., Marshall, B. D., et al. (2010b). Site-specific effects on respiratory rhythm and pattern of ibotenic acid injections in the pontine respiratory group of goats. J. Appl. Physiol. 109, $171-188$.

Bonnet, M. H. (1985). Effect of sleep disruption on sleep, performance, and mood. Sleep 8, 11-19. doi: 10.1093/sleep/8.1.11

Bonsignore, M. R., Esquinas, C., Barcelo, A., Sanchez-de-la-Torre, M., Paterno, A., Duran-Cantolla, J., et al. (2012). Metabolic syndrome, insulin resistance and sleepiness in real-life obstructive sleep apnoea. Eur. Respir. J. 39, 1136-1143. doi: 10.1183/09031936.00151110

Buchanan, G. F., and Richerson, G. B. (2010). Central serotonin neurons are required for arousal to CO2. Proc. Natl. Acad. Sci. U.S.A. 107, 16354-16359. doi: $10.1073 /$ pnas. 1004587107

Buchanan, G. F., Smith, H. R., MacAskill, A., and Richerson, G. B. (2015). 5-HT2A receptor activation is necessary for CO2-induced arousal. J. Neurophysiol. 114, 233-243. doi: 10.1152/jn.00213.2015

Campos, C. A., Bowen, A. J., Roman, C. W., and Palmiter, R. D. (2018). Encoding of danger by parabrachial CGRP neurons. Nature 555, 617-622. doi: 10.1038/ nature25511

Campos, C. A., Bowen, A. J., Schwartz, M. W., and Palmiter, R. D. (2016). Parabrachial CGRP neurons control meal termination. Cell Metab. 23, 811-820. doi: 10.1016/j.cmet.2016.04.006

Cape, E. G., and Jones, B. E. (2000). Effects of glutamate agonist versus procaine microinjections into the basal forebrain cholinergic cell area upon gamma and theta EEG activity and sleep-wake state. Eur. J. Neurosci. 12, 2166-2184. doi: 10.1046/j.1460-9568.2000.00099.x

Carr, F. B., and Zachariou, V. (2014). Nociception and pain: lessons from optogenetics. Front. Behav. Neurosci. 8:69. doi: 10.3389/fnbeh.2014.00069

Carter, M. E., de Lecea, L., and Adamantidis, A. (2013a). Functional wiring of hypocretin and LC-NE neurons: implications for arousal. Front. Behav. Neurosci. 7:43. doi: 10.3389/fnbeh.2013.00043

Carter, M. E., Soden, M. E., Zweifel, L. S., and Palmiter, R. D. (2013b). Genetic identification of a neural circuit that suppresses appetite. Nature 503, 111-114. doi: $10.1038 /$ nature 12596

Carter, M. E., Han, S., and Palmiter, R. D. (2015). Parabrachial calcitonin generelated peptide neurons mediate conditioned taste aversion. J. Neurosci. 35, 4582-4586. doi: 10.1523/JNEUROSCI.3729-14.2015

Carter, M. E., Yizhar, O., Chikahisa, S., Nguyen, H., Adamantidis, A., Nishino, S., et al. (2010). Tuning arousal with optogenetic modulation of 
locus coeruleus neurons. Nat. Neurosci. 13, 1526-1533. doi: 10.1038/nn. 2682

Chamberlin, N. L. (2004). Functional organization of the parabrachial complex and intertrigeminal region in the control of breathing. Respir. Physiol. Neurobiol. 143, 115-125. doi: 10.1016/j.resp.2004.03.015

Chamberlin, N. L., and Saper, C. B. (1994). Topographic organization of respiratory responses to glutamate microstimulation of the parabrachial nucleus in the rat. J. Neurosci. 14, 6500-6510. doi: 10.1523/jneurosci.14-11-06500. 1994

Corcoran, A. E., Hodges, M. R., Wu, Y., Wang, W., Wylie, C. J., Deneris, E. S., et al. (2009). Medullary serotonin neurons and central CO2 chemoreception. Respir. Physiol. Neurobiol. 168, 49-58. doi: 10.1016/j.resp.2009. 04.014

Damasceno, R. S., Takakura, A. C., and Moreira, T. S. (2014). Regulation of the chemosensory control of breathing by Kolliker-Fuse neurons. Am. J. Physiol. Regul. Integr. Comp. Physiol. 307, R57-R67. doi: 10.1152/ajpregu.00024. 2014

Darquenne, C., Elliott, A. R., Sibille, B., Smales, E. T., DeYoung, P. N., Theilmann, R. J., et al. (2018). Upper airway dynamic imaging during tidal breathing in awake and asleep subjects with obstructive sleep apnea and healthy controls. Physiol. Rep. 6:e13711. doi: 10.14814/phy2.13711

Datta, S., and Siwek, D. F. (1997). Excitation of the brain stem pedunculopontine tegmentum cholinergic cells induces wakefulness and REM sleep. J. Neurophysiol. 77, 2975-2988. doi: 10.1152/jn.1997.77.6.2975

Dean, J. B., Lawing, W. L., and Millhorn, D. E. (1989). CO2 decreases membrane conductance and depolarizes neurons in the nucleus tractus solitarii. Exp. Brain Res. 76, 656-661. doi: 10.1007/bf00248922

Depuy, S. D., Kanbar, R., Coates, M. B., Stornetta, R. L., and Guyenet, P. G. (2011). Control of breathing by raphe obscurus serotonergic neurons in mice. J. Neurosci. 31, 1981-1990. doi: 10.1523/JNEUROSCI.4639-10.2011

Diaz-Casares, A., Lopez-Gonzalez, M. V., Peinado-Aragones, C. A., GonzalezBaron, S., and Dawid-Milner, M. S. (2012). Parabrachial complex glutamate receptors modulate the cardiorespiratory response evoked from hypothalamic defense area. Auton. Neurosci. 169, 124-134. doi: 10.1016/j.autneu.2012.06.001

Dobbins, E. G., and Feldman, J. L. (1994). Brainstem network controlling descending drive to phrenic motoneurons in rat. J. Comp. Neurol. 347, 64-86. doi: $10.1002 / \mathrm{cne} .903470106$

Drager, L. F., Jun, J. C., and Polotsky, V. Y. (2010). Metabolic consequences of intermittent hypoxia: relevance to obstructive sleep apnea. Best Pract. Res. Clin. Endocrinol. Metab. 24, 843-851. doi: 10.1016/j.beem.2010.08.011

Feldman, J. L., Cohen, M. I., and Wolotsky, P. (1976). Powerful inhibition of pontine respiratory neurons by pulmonary afferent activity. Brain Res. 104, 341-346. doi: 10.1016/0006-8993(76)90629-6

Finley, J. C., and Katz, D. M. (1992). The central organization of carotid body afferent projections to the brainstem of the rat. Brain Res. 572, 108-116. doi: 10.1016/0006-8993(92)90458-1

Fletcher, E. C. (1996). Obstructive sleep apnoea and cardiovascular morbidity. Monaldi Arch. Chest Dis. 51, 77-80.

Fuller, P., Sherman, D., Pedersen, N. P., Saper, C. B., and Lu, J. (2011). Reassessment of the structural basis of the ascending arousal system. J. Comp. Neurol. 519, 933-956. doi: 10.1002/cne.22559

Fuller, P. M., Saper, C. B., and Lu, J. (2007). The pontine REM switch: past and present. J. Physiol. 584, 735-741. doi: 10.1113/jphysiol.2007.140160

Fuller, P. M., Yamanaka, A., and Lazarus, M. (2015). How genetically engineered systems are helping to define, and in some cases redefine, the neurobiological basis of sleep and wake. Temperature 2, 406-417. doi: 10.1080/23328940.2015. 1075095

Fulwiler, C. E., and Saper, C. B. (1984). Subnuclear organization of the efferent connections of the parabrachial nucleus in the rat. Brain Res. 319, 229-259. doi: 10.1016/0165-0173(84)90012-2

Geerling, J. C., Yokota, S., Rukhadze, I., Roe, D., and Chamberlin, N. L. (2017). Kolliker-Fuse GABAergic and glutamatergic neurons project to distinct targets. J. Comp. Neurol. 525, 1844-1860. doi: 10.1002/cne.24164

Gleeson, K., Zwillich, C. W., and White, D. P. (1990). The influence of increasing ventilatory effort on arousal from sleep. Am. Rev. Respir. Dis. 142, 295-300. doi: 10.1164/ajrccm/142.2.295

Gonzalez, C., Agapito, M. T., Rocher, A., Gomez-Nino, A., Rigual, R., Castaneda, J., et al. (2010). A revisit to $\mathrm{O} 2$ sensing and transduction in the carotid body chemoreceptors in the context of reactive oxygen species biology. Respir. Physiol. Neurobiol. 174, 317-330. doi: 10.1016/j.resp.2010. 09.002

Guyenet, P. G., and Bayliss, D. A. (2015). Neural control of breathing and CO2 homeostasis. Neuron 87, 946-961. doi: 10.1016/j.neuron.2015.08.001

Guyenet, P. G., Stornetta, R. L., Abbott, S. B., Depuy, S. D., Fortuna, M. G., and Kanbar, R. (2010a). Central CO2 chemoreception and integrated neural mechanisms of cardiovascular and respiratory control. J. Appl. Physiol. 108, 995-1002. doi: 10.1152/japplphysiol.00712.2009

Guyenet, P. G., Stornetta, R. L., and Bayliss, D. A. (2010b). Central respiratory chemoreception. J. Comp. Neurol. 518, 3883-3906. doi: 10.1002/cne.22435

Han, S., Soleiman, M. T., Soden, M. E., Zweifel, L. S., and Palmiter, R. D. (2015). Elucidating an affective pain circuit that creates a threat memory. Cell 162, 363-374. doi: 10.1016/j.cell.2015.05.057

Hayashi, Y., Kashiwagi, M., Yasuda, K., Ando, R., Kanuka, M., Sakai, K., et al. (2015). Cells of a common developmental origin regulate REM/non-REM sleep and wakefulness in mice. Science 350, 957-961. doi: 10.1126/science.aad1023

Herbert, H., Moga, M. M., and Saper, C. B. (1990). Connections of the parabrachial nucleus with the nucleus of the solitary tract and the medullary reticular formation in the rat. J. Comp. Neurol. 293, 540-580. doi: 10.1002/cne. 902930404

Holmes, C. J., and Jones, B. E. (1994). Importance of cholinergic, GABAergic, serotonergic and other neurons in the medial medullary reticular formation for sleep-wake states studied by cytotoxic lesions in the cat. Neuroscience 62, 1179-1200. doi: 10.1016/0306-4522(94)90352-2

Horner, R. L., Grace, K. P., and Wellman, A. (2017). A resource of potential drug targets and strategic decision-making for obstructive sleep apnoea pharmacotherapy. Respirology 22, 861-873. doi: 10.1111/resp.13079

Horner, R. L., Innes, J. A., Murphy, K., and Guz, A. (1991). Evidence for reflex upper airway dilator muscle activation by sudden negative airway pressure in man. J. Physiol. 436, 15-29. doi: 10.1113/jphysiol.1991.sp018536

Hunt, N. J., Russell, B., Du, M. K., Waters, K. A., and Machaalani, R. (2016). Changes in orexinergic immunoreactivity of the piglet hypothalamus and pons after exposure to chronic postnatal nicotine and intermittent hypercapnic hypoxia. Eur. J. Neurosci. 43, 1612-1622. doi: 10.1111/ejn.13246

Izumizaki, M., Pokorski, M., and Homma, I. (2004). Role of the carotid bodies in chemosensory ventilatory responses in the anesthetized mouse. J. Appl. Physiol. 97, 1401-1407. doi: 10.1152/japplphysiol.00025.2004

Jones, B. E. (2005). From waking to sleeping: neuronal and chemical substrates. Trends Pharmacol. Sci. 26, 578-586. doi: 10.1016/j.tips.2005.09.009

Jones, B. E., Bobillier, P., Pin, C., and Jouvet, M. (1973). The effect of lesions of catecholamine-containing neurons upon monoamine content of the brain and EEG and behavioral waking in the cat. Brain Res. 58, 157-177. doi: 10.1016/ 0006-8993(73)90830-5

Jun, J., and Polotsky, V. Y. (2009). Metabolic consequences of sleep-disordered breathing. ILAR J. 50, 289-306. doi: 10.1093/ilar.50.3.289

Kaur, S., Khanday, M. A., Bandaru, S. S., Todd, W. D., Fuller, P. M., and Saper, C. B. (2018). Serotonergic dorsal raphe neurons and the neuronal circuit for the hypercapnia induced arousal. Sleep 41(Suppl._1):A27.

Kaur, S., Pedersen, N. P., Yokota, S., Hur, E. E., Fuller, P. M., Lazarus, M., et al. (2013). Glutamatergic signaling from the parabrachial nucleus plays a critical role in hypercapnic arousal. J. Neurosci. 33, 7627-7640. doi: 10.1523/ JNEUROSCI.0173-13.2013

Kaur, S., Wang, J. L., Ferrari, L., Thankachan, S., Kroeger, D., Venner, A., et al. (2017). A genetically defined circuit for arousal from sleep during hypercapnia. Neuron 96, 1153-1167. doi: 10.1016/j.neuron.2017.10.009

Kleiner, S., and Bringmann, A. (1996). Nucleus basalis magnocellularis and pedunculopontine tegmental nucleus: control of the slow EEG waves in rats. Arch. Ital. Biol. 134, 153-167.

Lindsey, B. G., Nuding, S. C., Segers, L. S., and Morris, K. F. (2018). Carotid bodies and the integrated cardiorespiratory response to hypoxia. Physiology 33, 281-297. doi: 10.1152/physiol.00014.2018

Loredo, J. S., Ziegler, M. G., Ancoli-Israel, S., Clausen, J. L., and Dimsdale, J. E. (1999). Relationship of arousals from sleep to sympathetic nervous system activity and BP in obstructive sleep apnea. Chest 116, 655-659. doi: 10.1378/ chest.116.3.655

Lu, J., Sherman, D., Devor, M., and Saper, C. B. (2006). A putative flip-flop switch for control of REM sleep. Nature 441, 589-594. doi: 10.1038/nature04767 
Malhotra, A., and Loscalzo, J. (2009). Sleep and cardiovascular disease: an overview. Prog. Cardiovasc. Dis. 51, 279-284. doi: 10.1016/j.pcad.2008.10.004

Malhotra, A., and White, D. P. (2002). Obstructive sleep apnoea. Lancet 360, 237-245.

Mannarino, M. R., Di, F. F., and Pirro, M. (2012). Obstructive sleep apnea syndrome. Eur. J. Intern. Med. 23, 586-593. doi: 10.1016/j.ejim.2012.05.013

Massari, V. J., Shirahata, M., Johnson, T. A., and Gatti, P. J. (1996). Carotid sinus nerve terminals which are tyrosine hydroxylase immunoreactive are found in the commissural nucleus of the tractus solitarius. J. Neurocytol. 25, 197-208. doi: $10.1007 /$ bf 02284796

Miura, M., and Takayama, K. (1991). Circulatory and respiratory responses to glutamate stimulation of the lateral parabrachial nucleus of the cat. J. Auton. Nerv. Syst. 32, 121-133. doi: 10.1016/0165-1838(91)90062-8

Mizusawa, A., Ogawa, H., Kikuchi, Y., Hida, W., and Shirato, K. (1995). Role of the parabrachial nucleus in ventilatory responses of awake rats. J. Physiol. 489(Pt 3), 877-884. doi: 10.1113/jphysiol.1995.sp021100

Palmiter, R. D. (2018). The parabrachial nucleus: CGRP neurons function as a general alarm. Trends Neurosci. 41, 280-293. doi: 10.1016/j.tins.2018.03.007

Panneton, W. M., and Loewy, A. D. (1980). Projections of the carotid sinus nerve to the nucleus of the solitary tract in the cat. Brain Res. 191, 239-244. doi: 10.1016/0006-8993(80)90326-1

Park, H. G., and Carmel, J. B. (2016). Selective manipulation of neural circuits. Neurotherapeutics 13, 311-324. doi: 10.1007/s13311-016-0425-7

Pete, G., Mack, S. O., Haxhiu, M. A., Walbaum, S., and Gauda, E. B. (2002). CO(2)induced c-Fos expression in brainstem preprotachykinin mRNA containing neurons. Respir. Physiol. Neurobiol. 130, 265-274. doi: 10.1016/s0034-5687(02) 00013-0

Pham, L. V., Schwartz, A. R., and Polotsky, V. Y. (2018). Integrating loop gain into the understanding of obstructive sleep apnea mechanisms. J. Physiol. 596, 3819-3820. doi: 10.1113/jp276590

Plummer, N. W., Ungewitter, E. K., Smith, K. G., Yao, H. H., and Jensen, P. (2017). A new mouse line for cell ablation by diphtheria toxin subunit A controlled by a Cre-dependent FLEx switch. Genesis 55:e23067. doi: 10.1002/dvg.23067

Qiu, M. H., Chen, M. C., Fuller, P. M., and Lu, J. (2016). Stimulation of the pontine parabrachial nucleus promotes wakefulness via extra-thalamic forebrain circuit nodes. Curr. Biol. 26, 2301-2312. doi: 10.1016/j.cub.2016.07.054

Ray, R. S., Corcoran, A. E., Brust, R. D., Kim, J. C., Richerson, G. B., Nattie, E., et al. (2011). Impaired respiratory and body temperature control upon acute serotonergic neuron inhibition. Science 333, 637-642. doi: 10.1126/science. 1205295

Ray, R. S., Corcoran, A. E., Brust, R. D., Soriano, L. P., Nattie, E. E., and Dymecki, S. M. (2013). Egr2-neurons control the adult respiratory response to hypercapnia. Brain Res. 1511, 115-125. doi: 10.1016/j.brainres.2012.12.017

Richerson, G. B., Wang, W., Hodges, M. R., Dohle, C. I., and Diez-Sampedro, A. (2005). Homing in on the specific phenotype(s) of central respiratory chemoreceptors. Exp. Physiol. 90, 259-266. doi: 10.1111/j.1469-445x.2005. 00135.x

Richerson, G. B., Wang, W., Tiwari, J., and Bradley, S. R. (2001). Chemosensitivity of serotonergic neurons in the rostral ventral medulla. Respir. Physiol. 129, 175-189. doi: 10.1016/s0034-5687(01)00289-4

Rodrigues, L. T. C., da Silva, E. N., Horta-Junior, J. A. C., Gargaglioni, L. H., and Dias, M. B. (2019). Glutamate metabotropic receptors in the lateral hypothalamus/perifornical area reduce the $\mathrm{CO} 2$ chemoreflex. Respir. Physiol. Neurobiol. 260, 122-130. doi: 10.1016/j.resp.2018.11.007

Roman, C. W., Derkach, V. A., and Palmiter, R. D. (2016). Genetically and functionally defined NTS to PBN brain circuits mediating anorexia. Nat. Commun. 7:11905. doi: 10.1038/ncomms11905

Rosin, D. L., Chang, D. A., and Guyenet, P. G. (2006). Afferent and efferent connections of the rat retrotrapezoid nucleus. J. Comp. Neurol. 499, 64-89. doi: $10.1002 / \mathrm{cne} .21105$

Sands, S. A., Terrill, P. I., Edwards, B. A., Taranto, M. L., Azarbarzin, A., Marques, M., et al. (2018). Quantifying the arousal threshold using polysomnography in obstructive sleep apnea. Sleep 41:zsx183. doi: 10.1093/sleep/zsx183

Saper, C. B. (1982). Reciprocal parabrachial-cortical connections in the rat. Brain Res. 242, 33-40. doi: 10.1016/0006-8993(82)90493-0

Saper, C. B. (2016). The house alarm. Cell Metab. 23, 754-755. doi: 10.1016/j.cmet. 2016.04.021
Saper, C. B., and Fuller, P. M. (2017). Wake-sleep circuitry: an overview. Curr. Opin. Neurobiol. 44, 186-192. doi: 10.1016/j.conb.2017.03.021

Saper, C. B., and Loewy, A. D. (1980). Efferent connections of the parabrachial nucleus in the rat. Brain Res. 197, 291-317. doi: 10.1016/0006-8993(80)91117-8

Schnutgen, F., Doerflinger, N., Calleja, C., Wendling, O., Chambon, P., and Ghyselinck, N. B. (2003). A directional strategy for monitoring Cre-mediated recombination at the cellular level in the mouse. Nat. Biotechnol. 21, 562-565. doi: $10.1038 /$ nbt811

Schulz, R. (2010). [Obstruction of the upper airways in humans and animal models]. Pneumologie 64, 447-449. doi: 10.1055/s-0030- 1255511

Semba, K., and Fibiger, H. C. (1992). Afferent connections of the laterodorsal and the pedunculopontine tegmental nuclei in the rat: a retro- and antero-grade transport and immunohistochemical study. J. Comp. Neurol. 323, 387-410. doi: $10.1002 /$ cne. 903230307

Smith, H. R., Leibold, N. K., Rappoport, D. A., Ginapp, C. M., Purnell, B. S., Bode, N. M., et al. (2018). Dorsal raphe serotonin neurons mediate CO2-induced arousal from sleep. J. Neurosci. 38, 1915-1925. doi: 10.1523/JNEUROSCI.218217.2018

Smith, H. R., Richerson, G. B., and Buchanan, G. F. (2012). Activation of 5$H T_{2 \mathrm{~A}}$ Receptors Recovers Hypercapnia-Induced Arousal in Genetically Central 5-HT Neuron Deficient Mice. Abstract- 799.07. Washington, DC: Society for Neuroscience.

Song, G., and Poon, C. S. (2009). Lateral parabrachial nucleus mediates shortening of expiration and increase of inspiratory drive during hypercapnia. Respir. Physiol. Neurobiol. 165, 9-12. doi: 10.1016/j.resp.2008.10.009

Stanic, D., Dhingra, R. R., and Dutschmann, M. (2018). Expression of the transcription factor FOXP2 in brainstem respiratory circuits of adult rat is restricted to upper-airway pre-motor areas. Respir. Physiol. Neurobiol. 250, 14-18. doi: 10.1016/j.resp.2018.01.014

Steriade, M., Amzica, F., and Nunez, A. (1993). Cholinergic and noradrenergic modulation of the slow (approximately $0.3 \mathrm{~Hz}$ ) oscillation in neocortical cells. J. Neurophysiol. 70, 1385-1400. doi: 10.1152/jn.1993.70.4. 1385

Todd, W. D., Fenselau, H., Wang, J. L., Zhang, R., Machado, N. L., Venner, A., et al. (2018). A hypothalamic circuit for the circadian control of aggression. Nat. Neurosci. 21, 717-724. doi: 10.1038/s41593-018-0126-0

Topchiy, I., Waxman, J., Radulovacki, M., and Carley, D. W. (2010). Functional topography of respiratory, cardiovascular and pontine-wave responses to glutamate microstimulation of the pedunculopontine tegmentum of the rat. Respir. Physiol. Neurobiol. 173, 64-70. doi: 10.1016/j.resp.2010. 06.006

Vlasov, K., Van Dort, C. J., and Solt, K. (2018). Optogenetics and chemogenetics. Methods Enzymol. 603, 181-196. doi: 10.1016/bs.mie.2018. 01.022

Wang, D., Piper, A. J., Yee, B. J., Wong, K. K., Kim, J. W., D’Rozario, A., et al. (2014). Hypercapnia is a key correlate of EEG activation and daytime sleepiness in hypercapnic sleep disordered breathing patients. J. Clin. Sleep Med. 10, 517-522. doi: 10.5664/jcsm.3700

Wang, D., Thomas, R. J., Yee, B. J., and Grunstein, R. R. (2016). Last Word on Viewpoint: hypercapnia is more important than hypoxia in the neurooutcomes of sleep-disordered breathing. J. Appl. Physiol. 120:1489. doi: 10. 1152/japplphysiol.00354.2016

Whissell, P. D., Tohyama, S., and Martin, L. J. (2016). The use of DREADDs to deconstruct behavior. Front. Genet. 7:70. doi: 10.3389/fgene.2016.00070

White, D. P. (2006). The pathogenesis of obstructive sleep apnea: advances in the past 100 years. Am. J. Respir. Cell Mol. Biol. 34, 1-6. doi: 10.1165/rcmb.20050317oe

White, D. P. (2017). Advanced concepts in the pathophysiology of obstructive sleep apnea. Adv. Otorhinolaryngol. 80, 7-16. doi: 10.1159/000470522

White, D. P., and Younes, M. K. (2012). Obstructive sleep apnea. Compr. Physiol. 2, 2541-2594. doi: 10.1002/cphy.c110064

Wu, Q., Han, Y., and Tong, Q. (2018). Current genetic techniques in neural circuit control of feeding and energy metabolism. Adv. Exp. Med. Biol. 1090, 211-233. doi: 10.1007/978-981-13-1286-1_12

Yang, C. F., and Feldman, J. L. (2018). Efferent projections of excitatory and inhibitory preBotzinger Complex neurons. J. Comp. Neurol. 526, 1389-1402. doi: $10.1002 /$ cne. 24415 
Yasui, Y., Saper, C. B., and Cechetto, D. F. (1991). Calcitonin gene-related peptide (CGRP) immunoreactive projections from the thalamus to the striatum and amygdala in the rat. J. Comp. Neurol. 308, 293-310. doi: 10.1002/cne.9030 80212

Yokota, S., Kaur, S., Van der Horst, V., Chamberlin, N. L., and Saper, C. B. (2012). Mouse parabrachial neurons projecting to the rostral ventral respiratory group, phrenic and hypoglossal neurons are activated by hypercapnia. Sleep 35(Abstract Suppl.):A-44.

Yokota, S., Kaur, S., VanderHorst, V. G., Saper, C. B., and Chamberlin, N. L. (2015). Respiratory-related outputs of glutamatergic, hypercapnia-responsive parabrachial neurons in mice. J. Comp. Neurol. 523, 907-920. doi: 10.1002/cne. 23720

Yokota, S., Tsumori, T., Ono, K., and Yasui, Y. (2001). Phrenic motoneurons receive monosynaptic inputs from the Kolliker-Fuse nucleus: a light- and electronmicroscopic study in the rat. Brain Res. 888, 330-335. doi: 10.1016/s00068993(00)03106-1
Zinchuk, A., Edwards, B. A., Jeon, S., Koo, B. B., Concato, J., Sands, S., et al. (2018). Prevalence, associated clinical features, and impact on continuous positive airway pressure use of a low respiratory arousal threshold among male united states veterans with obstructive sleep apnea. J. Clin. Sleep Med. 14, 809-817. doi: $10.5664 /$ jcsm. 7112

Conflict of Interest Statement: The authors declare that the research was conducted in the absence of any commercial or financial relationships that could be construed as a potential conflict of interest.

Copyright $\odot 2019$ Kaur and Saper. This is an open-access article distributed under the terms of the Creative Commons Attribution License (CC BY). The use, distribution or reproduction in other forums is permitted, provided the original author(s) and the copyright owner(s) are credited and that the original publication in this journal is cited, in accordance with accepted academic practice. No use, distribution or reproduction is permitted which does not comply with these terms. 